\title{
Different proliferative activity of the glandular and myoepithelial lineages in benign proliferative and early malignant breast diseases
}

\author{
Agnes Bánkfalvi, Andreas Ludwig, Bettina de-Hesselle, Horst Buerger, Igor B Buchwalow
} and Werner Boecker

Institute of Pathology, Münster University Hospital, Münster, Germany

\begin{abstract}
The aim of the present study was to explore cell biological characteristics of normal breast, benign proliferative breast diseases and noninvasive breast malignancies based on the recently published adult progenitor cell concept from our group. Here, we investigated the proliferative activity of CK5/14 +, CK8/18/19 + and $\alpha$-smooth muscle actin + cellular phenotypes encountered in normal mammary gland, in a series of usual ductal hyperplasias and early malignant breast diseases, such as atypical ductal and lobular hyperplasias, as well as ductal and lobular in situ carcinomas. Immunohistochemical double labeling was performed on frozen sections from diagnostic breast biopsies by using antibodies to basal cytokeratins (CK5/14), glandular cytokeratins (CK8/18/19), smooth muscle actin and the Ki-67 antigen (MIB1). Normal breast tissues and usual ductal hyperplasias were characterized by a heterogeneous cellular composition of the growth fraction. The proliferative cell compartment consisted of CK8/18/19 + glandular and, in a variable proportion, CK5/14+ progenitor phenotypes. In contrast, noninvasive breast malignancies were composed of a monotonous proliferation of CK 8/18/19 + neoplastic glandular cells. These findings indicate a significant role of progenitor cells in the development of benign proliferative breast diseases and lend support to the view that malignant transformation in the human breast usually occurs in a cell committed to the glandular lineage. Our results provide cell kinetic support to the functional progenitor cell hypothesis, and we propose this concept as an operative model for understanding benign proliferative and malignant breast diseases.
\end{abstract}

Modern Pathology (2004) 17, 1051-1061, advance online publication, 2 July 2004; doi:10.1038/modpathol.3800082

Keywords: breast; ductal hyperplasia; carcinoma in situ; proliferation; progenitor cell model

The normal human breast epithelium has originally been described to be composed of two morphologically separate cell populations: luminal glandular cells and basal myoepithelial cells. ${ }^{1}$ In tissue sections, these cells can be discriminated by their localization and by the expression of simple type I keratins (CK8/18/19) and smooth muscle actin, respectively. ${ }^{2-4}$ This two-cell paradigm has shaped successfully our understanding of pathological processes in the human breast over many decades.

Correspondence: Dr W Boecker, MD, Department of Pathology, Gerhard-Domagk-Institute of Pathology, University of Münster, Domagkstrasse 17, D-48149 Münster, Germany.

E-mail: boeckew@uni-muenster.de

This study contains parts of the doctoral theses of Andreas Ludwig and Bettina de-Hessele.

Received 21 March 2003; revised 28 October 2003; accepted 11 November 2003; published online 2 July 2004
However, there is a growing body of evidence indicating that this two-cell model is too simplistic and the breast has a more complicated cellular structure with an integrated cellular renewal system of breast epithelium, similarly to the human prostate and skin epidermis. ${ }^{5-7}$ Over the last decades, ultrastructural, immunohistochemical, in vitro and gene expression studies identified a third cell type in the normal breast, in addition to CK8/18/ $19+$ glandular- and smooth muscle actin + myoepithelial cells. This cell type expresses basal cell-specific keratins CK5/14 and is located both in the basal/parabasal layers and in the luminal compartment. ${ }^{4,8-11}$ These cells were first interpreted as being myoepithelial cells, later they were proposed to represent progenitor cells in the human breast. $^{12}$ Most recently, we provided evidence by double-immunofluorescence labeling and Western blot analysis for the existence of CK5/14+ progenitor cells within the breast 
epithelium, which have the property to differentiate into glandular and myoepithelial cells via intermediary hybrid progenies. ${ }^{13}$ This functional progenitor cell model has been shown to be helpful in explaining and distinguishing different types of intraductal epithelial proliferations such as usual ductal hyperplasia as well as ductal- and lobular in situ malignancies ${ }^{14}$ and invasive breast cancer. ${ }^{15}$ Furthermore, it seems to underlie the biological and morphological heterogeneity of benign proliferative breast diseases and helps to elucidate the pathways in breast carcinogenesis, as well.

In the present study, we used double-label immunohistochemical protocols for colocalization of the proliferation-associated Ki-67 antigen with glandular keratins (CK8/18/19), basal keratins (CK5/ 14) and $\alpha$-smooth muscle actin, ${ }^{9,10}$ in order to assess the proliferative activity of different immunophenotypes in normal breast, usual ductal hyperplasia, atypical ductal and lobular hyperplasias, ductal and lobular in situ carcinomas. In the group of ductal carcinoma in situ, we focused on non-high-grade lesions.

\section{Materials and methods}

\section{Tissues and Diagnosis}

Diagnostic breast tissue specimens from biopsies and lumpectomies were obtained from 19 female patients (mean age 53 years, ranging from 30 to 68 years) undergoing operation at the Department of Gynecology and Obstetrics at the University Hospital in Münster, Germany. To each case, both routinely processed paraffin-embedded material and snap-frozen tissues were available at the DomagkInstitute of Pathology, University Hospital Münster. The lesions were classified by three pathologists on routinely hematoxylin-eosin-stained sections according to current classification protocols. ${ }^{16-20}$ Atypical ductal hyperplasia was defined as tiny focal proliferation of evenly spaced cells with monotonous round to oval nuclei confined to lobules. ${ }^{20}$ DCIS was graded according to the classification of Holland et al. ${ }^{17}$ Most histological samples contained several distinct lesions in close proximity resulting in a total of 394 diagnoses: 55 foci with normal breast parenchyma, 76 adenoses, 26 fibrocystic changes, 55 usual ductal hyperplasias, 33 atypical ductal hyperplasias, 94 ductal carcinomas in situ non-high grade, 28 atypical lobular hyperplasias and 25 lobular carcinomas in situ.

\section{Immunohistochemistry}

Serial cryostat sections, $5 \mu \mathrm{m}$ thick, were cut, airdried overnight and fixed in acetone for $10 \mathrm{~min}$ at room temperature. Cells with different immunophenotypes were identified by using antibodies against smooth muscle actin, simple keratins CK8/18/19 and basal keratins CK5/14, respectively. Proliferating cells were labeled by a monoclonal anti-Ki-67 (MIB1) antibody. Primary antibodies used are listed in Table 1.

To assess the proliferation rate of cells with different immunophenotypes within different lesions, a sequential double-immunostaining was performed. In the first sequence, the monoclonal MIB1 antibody was applied on three serial sections from each specimen and detected by the standard peroxidase-anti-peroxidase technique using 3,3diaminobenzidine tetrahydrochloride (DAB) as chromogen. In the second sequence, separate staining of CK5/14, CK 8/18/19 and $\alpha$-smooth muscle actin was carried out on the MIB1-stained sections by the alkaline phosphatase-anti-alkaline phosphatase method using New-Fuchsin as chromogen (Sigma, Munich, Germany), according to standard protocols. Secondary and tertiary antibodies were purchased from Dakopatts and Dianova (Hamburg, Germany). Omission of primary antibodies and replacement with mouse and rabbit IgGs, respectively, served as controls. Finally, slides were counterstained with hematoxylin and mounted with Permount (Sigma, Munich, Germany).

Additionally, three corresponding routinely formalin-fixed and paraffin-embedded specimens with representative lesions from each diagnostic group were stained by double-fluorescence immunolabeling using primary monoclonal mouse antibodies specific for CK5/6, CK8/18/19 and smooth muscle actin. Secondary and tertiary immunoreactions were performed by using FITC and Cy3-labeled immunoreagents as described elsewhere in detail. ${ }^{13,14}$ These investigations were carried out in order to compare directly results of the present study with previous

Table 1 Primary antibodies

\begin{tabular}{lllc}
\hline Specificity & Antibody & Source & Working dilution \\
\hline CK5/14 & Clone: KA1; mouse monoclonal Ab; IgG1 & Dr RB Nagle & $1: 2000$ \\
CK5/6 & Clone: D5/16B4; mouse monoclonal antibody & Dako, Hamburg, Germany & $1: 80$ \\
CK8, 18,19 & Anti-TPA: B1; rabbit polyclonal antibody & AB Sangtec Medica Co., Bromma, Sweden & $1: 20$ \\
$\alpha$-Smooth muscle actin & Clone: HHF-35; mouse monoclonal Ab, IgG1 & Boehringer, Mannheim, FRG & $1: 4$ \\
Ki-67 & Clone: MIB1; mouse monoclonal Ab; IgG1 & Dianova, Hamburg Germany & $1: 100$
\end{tabular}

\footnotetext{
${ }^{\mathrm{a}}$ References in Nagle et al (1986), ${ }^{21}$ Böcker et al (1992) ${ }^{9,10}$ and Böcker et al (2002). ${ }^{13,14}$
} 
findings where the progenitor cell hypothesis had been formulated.

\section{Quantitation of Immunohistochemistry}

MIB1 growth fraction

MIB1 labeling indices were estimated as a percentage of positively stained nuclei of at least 100 cells counted in three or more viewing fields of a given lesion or foci of normal breast glands at a magnification of $\times 400$.

\section{Differential MIB1 growth fraction of different} epithelial lineages

The frequency rate of MIB1-positive cells among cells with progenitor (CK5/14+)-, glandular (CK8/ 18/19+)-, and myoepithelial (smooth muscle actin + ) phenotype was also calculated separately for each lesion.

MIB1 growth fraction of different epithelial lineages in the basal/suprabasal and luminal compartments The frequency rate of MIB1-positive cells within different lineage-specific immunophenotypes was separately assessed in the basal/parabasal and luminal compartments in a given anatomic structure, or lesion. Basal/suprabasal cells were defined as cells in contact with the basal lamina but with no free luminal surface; luminal epithelial cells had no basal lamina contact.

\section{Statistical Analysis}

Data were evaluated by using the SPSS 6.1 for Windows software. Descriptive statistics for continuous measures were given as the mean and/or the median with the respective standard deviation. Differences in proliferative activity (MIB1 labeling index) between the three epithelial phenotypes in the various diagnostic groups were analyzed by nonparametric tests (Kruskal-Wallis, Mann-Whitney $U$ and Wilcoxon, whenever appropriate).

\section{Fluorescence Microscopy and Image Processing}

Detailed description of the methodology has been previously published by our group. ${ }^{13,14}$ In brief, immunostained sections were examined on a Zeiss Axiophot fluorescence microscope (Carl Zeiss Werke, Germany) equipped by appropriate filters for DAPI, Cy3 and FITC. Separate images for the three different fluorescence colors were captured by an AxioCam digital camera and processed by using the AxioVision2.05 software (Carl Zeiss Vision GmBH, Munich-Hallbergmoos, Germany). Composite images were created and imported as JPEG files into Photoimpact 3.0 (Ulead Systems, Inc., Torrance, CA, USA) for further analysis.

\section{Results}

MIB1-positive cells displayed a diffuse brown nuclear staining of different intensity irrespective of the cell type. Immunoreactions with the anti-CK 5/14-, anti-CK 8/18/19- and anti-smooth muscle actin antibodies resulted in a red cytoplasmic and membrane staining according to the lineage-specific differentiation of the respective cells. In short, in normal resting breast tissue, the anti-CK8/18/19 antibody consistently reacted with the luminal lining epithelial cells of acini, ductules, ducts and lactiferous sinus. In contrast, the anti-CK5/14 antibody decorated the basal cells of the ductal-lobular structures and also stained a few luminal cells. The anti-smooth muscle actin antibody reacted exclusively with basal cells (for details, see Nagle et $a l^{21}$ ). Representative double labeling (peroxidase-antiperoxidase and alkaline phosphatase-anti-alkaline phosphatase) of the normal breast and different proliferative lesions are demonstrated in Figure 1.

\section{MIB1 Growth Fraction in Normal Breast Tissues, Benign Proliferative Breast Disease, and In Situ Carcinomas}

The mean and median values as well as the standard deviation of MIB1 labeling indices for the different diagnostic groups are demonstrated in Table 2 .

Benign breast lesions disclosed different average growth fractions ranging from $1.83 \%( \pm 2.64 \%)$ in normal breast tissue and $0.37 \%( \pm 0.99 \%)$ in fibrocystic lesions to $3.23 \%( \pm 3.39 \%)$ in adenosis. Adenosis showed higher average proliferation rate than usual ductal hyperplasia (mean $2.41 \pm 4.02 \%$ ). In the group of benign lesions, there was no statistically significant difference in proliferation activity between the different entities and normal breast tissue. In contrast, the average proliferation rate of non-high-grade ductal carcinoma in situ (mean $8.4 \pm 5.3 \%$ ) was statistically significantly higher than that of all benign lesions and normal breast tissues investigated.

\section{Differential MIB1 Growth Fraction of Different Epithelial Phenotypes in Normal Breast Tissues, Benign Proliferative and Early Malignant Breast Diseases}

MIB1 labeling indices for the different immunophenotypes in the different diagnostic groups are demonstrated in Table 3 and Figure 2. Frequency rates of different proliferating epithelial phenotypes in basal/suprabasal and luminal localization are shown in Table 4.

\section{Proliferative activity within the normal terminal duct lobular unit \\ In the normal breast, all three immunophenotypes showed immunoreactivity with the MIB1 antibody}



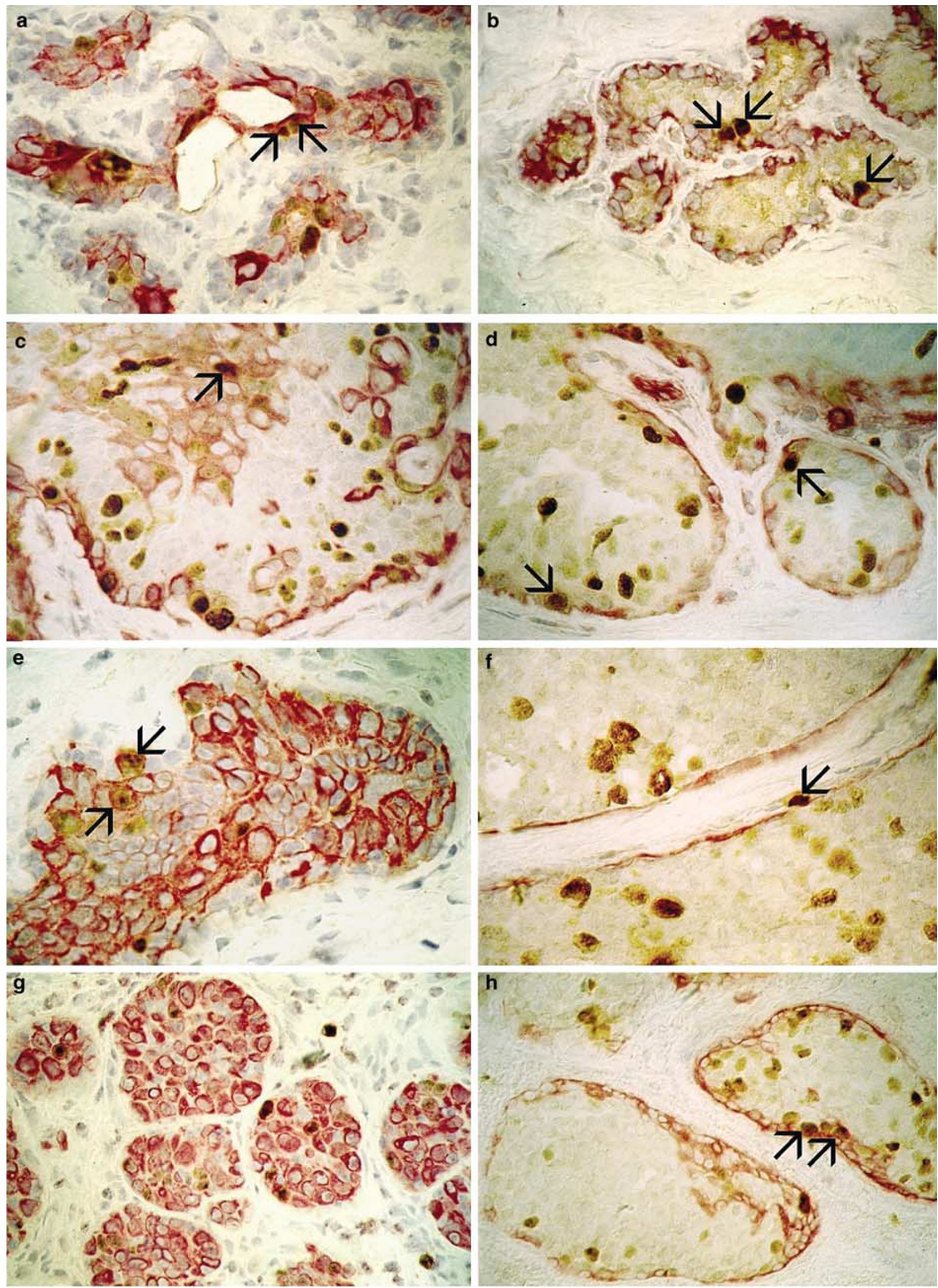
Table 2 MIB1 labeling indices in the different diagnostic groups

\begin{tabular}{|c|c|c|c|}
\hline Diagnosis & $\operatorname{Mean}(\%)(\min -\max )$ & Median (\%) & Standard deviation (\%) \\
\hline Normal breast & $1.83(0-11.93)$ & 0.99 & \pm 2.644 \\
\hline Fibrocystic lesion & $0.37(0-4.76)$ & 0 & \pm 0.99 \\
\hline Adenosis & $3.23(0-17.60)$ & 1.96 & \pm 3.39 \\
\hline Usual ductal hyperplasia & $2.41(0-20.64)$ & 0.99 & \pm 4.02 \\
\hline Ductal carcinoma in situ non-high grade & $8.40^{\mathrm{a}}(0-20.00)$ & $7.83^{\mathrm{a}}$ & \pm 5.32 \\
\hline
\end{tabular}

${ }^{\text {a }}$ Statistically significant difference compared to all benign lesions and normal breast.

Table 3 Differential MIB1 growth fraction in the different lineage-specific cell types

\begin{tabular}{|c|c|c|c|}
\hline Diagnosis & $\begin{array}{l}\text { MIB1+/CK8/18/19+ cells } \\
\text { median (min-max) (\%) }\end{array}$ & $\begin{array}{l}\text { MIB1+/CK5/14+ cells } \\
\text { median (min-max) (\%) }\end{array}$ & $\begin{array}{c}\text { MIB1+/smooth } \\
\text { muscle actin+ cells }\end{array}$ \\
\hline Normal breast & $\begin{array}{c}28 \\
(0-95)\end{array}$ & $\begin{array}{c}0 \\
(0-51)\end{array}$ & $+1-$ \\
\hline Adenosis & $\begin{array}{c}29 \\
(0-68)\end{array}$ & $\begin{array}{c}0 \\
(0-12)\end{array}$ & Scattered \\
\hline Usual ductal hyperplasia & $\begin{array}{c}22 \\
(0-52)\end{array}$ & $\begin{array}{c}14 \\
(0-68)\end{array}$ & Scattered \\
\hline Atypical ductal hyperplasia & $\begin{array}{c}40 \\
(0-95)\end{array}$ & $+1-$ & 0 \\
\hline Ductal carcinoma in situ, non-high grade & $\begin{array}{c}21 \\
(5-55)\end{array}$ & $+/-$ & 0 \\
\hline Atypical lobular hyperplasia & $\begin{array}{c}41 \\
(0-72)\end{array}$ & $\begin{array}{c}4 \\
(0-10)\end{array}$ & $+1-$ \\
\hline Lobular carcinoma in situ & $\begin{array}{c}42 \\
(18-70)\end{array}$ & $\begin{array}{c}2 \\
(0-18)\end{array}$ & $+/-$ \\
\hline
\end{tabular}

$+/-=$ only very few cells present.

in varying ratios and spatial distribution. The major component of the growth fraction was made up of MIB1 + /CK8/18/19 + glandular phenotypic cells (range 0-95\%; median 28\%) located both intraluminally and in the basal/suprabasal layers with luminal preference. A few proliferating cells with MIB1 + /CK5/14 + phenotype were seen both in the luminal and basal/suprabasal compartments in a range of $0-50$ and $0-32 \%$, respectively. Proliferating MIB1 + /smooth muscle actin + cells were observed sporadically and confined to the basal/suprabasal layers.
Proliferative activity of different epithelial phenotypes in bening proliferative breast diseases Benign proliferative lesions were composed of all epithelial phenotypes encountered in the normal mammary gland in remarkable cytomorphological and architectural diversity and proliferative heterogeneity.

Adenosis resembled very much normal glands in that the MIB1 + /CK8/18/19 + glandular phenotypic cell fraction represented the predominant proliferating compartment (mean: 29\%; range: 0-68\%) both luminally and in the basal/suprabasal layers with

Figure 1 Double-label immunohistochemistry (peroxidase-antiperoxidase and alkaline phosphatase-anti-alkaline phosphatase techniques) for co-localization of Ki-67 (brown nuclear staining) and CK8/18/19, CK5/14, smooth muscle actin (red cytoplasmic and membrane staining) in normal breast tissue and different proliferative lesions. (a) The inner glandular epithelium in normal breast acini consistently expresses CK8/18/19 (red staining) and contains also a few CK8/18/19 + /MIB1 + proliferating cells (brown nuclei pointed at by arrows). The outer basal layer is completely negative for both antibodies. (b) In adenosis, the outer basal cell layer and three suprabasal cells are positive for CK5/14; the latter three cells are also stained by the MIB1 antibody (arrows). (c) In usual ductal hyperplasia, the basal (myoepithelial) cells and also some luminal cells are positive for CK5/14, a few of them are also positive for MIB1. The arrow points at a luminal cell expressing CK5/14 and positive for MIB1. (d) Further, in usual ductal hyperplasia, smooth muscle actin decorates only the myoepithelial cells, a very few of them are also stained by the MIB1 antibody (arrow). (e) In atypical ductal hyperplasia, the majority of luminal epithelial cells are positive for CK8/18/19. The basal layer is almost completely negative for this cytokeratin. MIB1-positive cells occur mainly in the CK8/18/19+ luminal cell fraction. The arrows demonstrate one luminal and one basally located cells with CK8/18/19 + /MIB1 + immunophenotype. (f) In ductal carcinoma in situ, myoepithelial cells, but none of the luminal cells are consistently positive for CK5/14. Proliferation takes place in the luminal (CK5/14-) cell compartment. The arrow points at one basal cell with CK5/15 + /MIB1 + immunophenotype. (g) In atypical lobular hyperplasia, most luminal cells express CK8/18/19, some of them are also positive for MIB1. (h) In lobular carcinoma in situ, CK5/14 + cells can be found primarily in basal but also in a smaller amount in luminal localization. Proliferation takes place mainly in the luminal (CK5/14-) cell compartment. The arrows show two cells with CK5/14 +/MIB1 + immunophenotype, one in the basal layer and the other one in suprabasal localization. 


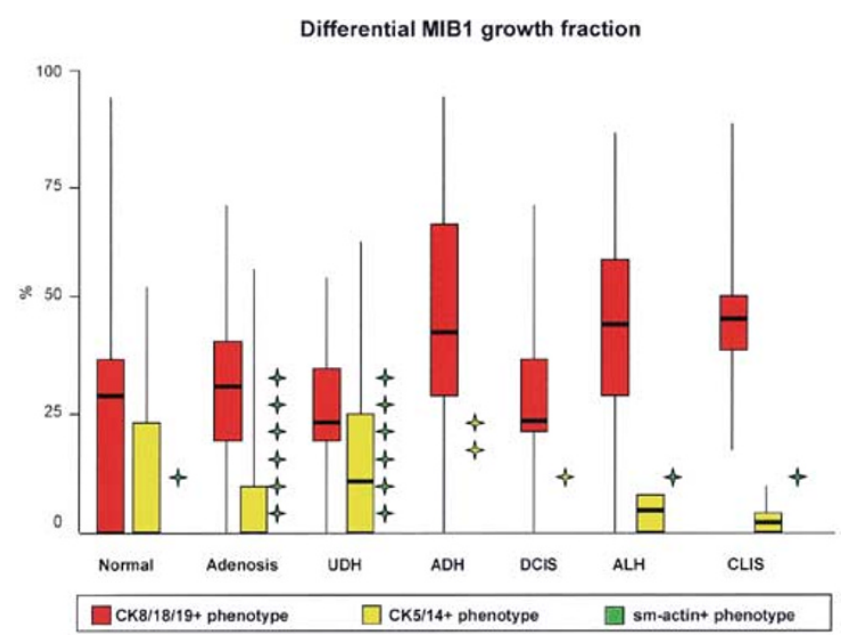

Figure 2 Differential MIB1 growth fractions of different epithelial phenotypes in normal breast tissues, benign proliferative- and early malignant breast diseases (atypical ductal hyperplasia, ductal carcinoma in situ, lobular carcinoma in situ). Abbreviations: $\mathrm{UDH}=$ usual ductal hyperplasia; $\mathrm{ADH}=$ atypical ductal hyperplasia; DCIS = ductal carcinoma in situ; ALH=atypical lobular hyperplasia; CLIS = lobular carcinoma in situ; smactin $=$ smooth muscle actin. Yellow stars: very few proliferating cells with MIB1 + /CK5/14 + phenotypes. Green stars: very few or dispersed proliferating cells with MIB1 +/smooth muscle actin + phenotypes.

luminal preference. A low proportion of proliferating MIB1 + /CK5/14 + phenotypes was also present (range: 0-13\%; median: 0) almost equally distributed in the luminal and basal/suprabasal strata. Additionally, there was a slightly increased proliferative rate of MIB1 + /smooth muscle actin + cells, exclusively in the basal and suprabasal layers.

Usual ductal hyperplasias were characterized by a mixed intraluminal proliferation of a heterogeneous epithelial cell population composed of a mixture of $\mathrm{MIB} 1+/ \mathrm{CK} 8 / 18 / 19+$ and MIB1 + /CK5/14 + immunophenotypes. A coexpression of the two cytokeratins in a variable number of intraluminal cells was unequivocally identified in double-immunofluorescence experiments (see below). The growth rate of $\mathrm{MIB} 1+/ \mathrm{CK} 8 / 18 / 19+$ cells was slightly decreased (median 22\%; range: $0-52 \%$ ), compared to normal breast and adenosis. The ratio of proliferating MIB1 + /CK5/14 + cells reached its highest level from among all lesions studied (median 14\%, range: $0-68 \%$ ). This increase was statistically significant $(P<0.01$; Mann-Whitney $U$-test $) . \quad R e-$ spective cells were observed predominantly luminal (median 17\%; range: $0-73 \%$ ) and in a very small proportion basal/suprabasal (median: 0; range: 0$51 \%)$. The range of MIB1 + /CK8/18/19 + cells was between $0-99 \%$ intraluminally and $0-60 \%$ in the basal/suprabasal layers (median: 22 and 20\%, respectively). Disseminated proliferating MIB1 + / smooth muscle actin + cells were only found in the basal/suprabasal compartment.

\section{Proliferative activity of different epithelial phenotypes in early malignant breast diseases and in situ carcinomas}

In contrast to the heterogeneous cellular composition of benign proliferative lesions, early malignant breast diseases (atypical ductal hyperplasia, atypical lobular hyperplasia) and in situ carcinomas (ductal carcinoma in situ non-high grade, lobular carcinoma in situ) were characterized by a monotonous proliferation of the CK8/18/19+ glandular phenotype, with significantly increased growth rates. The median growth rates of MIB1 + /CK8/18/ $19+$ cells in luminal location were $42 \%$ in atypical ductal hyperplasia, $18 \%$ in ductal carcinoma in situ, $50 \%$ in atypical lobular hyperplasia and $41 \%$ in lobular carcinoma in situ. Respective rates in the basal/suprabasal region were 25, 31, 32 and $48 \%$. There was a complete lack of proliferating MIB1 + / CK5/14 + phenotypes in the basal compartment of atypical ductal hyperplasia and ductal carcinoma in situ, with very few positive cells in luminal location in atypical ductal hyperplasia but not in ductal carcinoma in situ. In contrast, atypical lobular hyperplasia and lobular carcinoma in situ revealed a small fraction of proliferating MIB1+/CK5/14+

Table 4 Frequency rate of proliferating lineage-specific immunophenotypes in the luminal and basal/suprabasal cellular compartments (median and range in \%)

\begin{tabular}{|c|c|c|c|c|c|c|c|c|}
\hline & & $\begin{array}{l}\text { Normal median } \\
\text { (range) }\end{array}$ & $\begin{array}{c}\text { Adenosis median } \\
\text { (range) }\end{array}$ & $\begin{array}{l}\text { UDH median } \\
\text { (range) }\end{array}$ & $\begin{array}{l}\text { ADH median } \\
\text { (range) }\end{array}$ & $\begin{array}{l}\text { DCIS median } \\
\quad \text { (range) }\end{array}$ & $\begin{array}{l}\text { ALH Median } \\
\text { (range) }\end{array}$ & $\begin{array}{c}\text { CLIS median } \\
\text { (range) }\end{array}$ \\
\hline \multirow[t]{2}{*}{ MIB1+/CK5/14+ } & lum. & $\begin{array}{c}0 \\
(0-50)\end{array}$ & $\begin{array}{c}0 \\
(0-38)\end{array}$ & $\begin{array}{c}17 \\
(0-73)\end{array}$ & $\begin{array}{l}0 \\
+/-\end{array}$ & $\underline{0}$ & $\begin{array}{c}5 \\
(0-22)\end{array}$ & $\begin{array}{c}0 \\
(0-12)\end{array}$ \\
\hline & $\mathrm{b} / \mathrm{sb}$ & $\begin{array}{c}0 \\
(0-32)\end{array}$ & $\begin{array}{c}0 \\
(0-15)\end{array}$ & $\begin{array}{c}0 \\
(0-51)\end{array}$ & $\begin{array}{l}0 \\
0\end{array}$ & $\underline{0}$ & $\begin{array}{c}0 \\
(0-10)\end{array}$ & $\begin{array}{l}0 \\
+1-\end{array}$ \\
\hline \multirow[t]{2}{*}{ MIB1+/CK8/18/19+ } & lum. & $\begin{array}{c}29 \\
(0-99)\end{array}$ & $\begin{array}{c}28 \\
(0-99)\end{array}$ & $\begin{array}{c}22 \\
(0-99)\end{array}$ & $\begin{array}{c}42 \\
(0-99)\end{array}$ & $\begin{array}{c}18 \\
(0-48)\end{array}$ & $\begin{array}{c}50 \\
(0-80)\end{array}$ & $\begin{array}{c}41 \\
(20-62)\end{array}$ \\
\hline & $\mathrm{b} / \mathrm{sb}$ & $\begin{array}{c}20 \\
(0-99)\end{array}$ & $\begin{array}{c}22 \\
0-80\end{array}$ & $\begin{array}{c}20 \\
(0-60)\end{array}$ & $\begin{array}{c}25 \\
(0-75)\end{array}$ & $\begin{array}{c}31 \\
(0-99)\end{array}$ & $\begin{array}{c}32 \\
(0-82)\end{array}$ & $\begin{array}{c}48 \\
(0-99)\end{array}$ \\
\hline MIB1+/smooth & lum. & 0 & 0 & 0 & 0 & 0 & 0 & 0 \\
\hline muscle actin+ & $\mathrm{b} / \mathrm{sb}$ & $+1-$ & scatt. & scatt. & 0 & 0 & $+1-$ & $+1-$ \\
\hline
\end{tabular}

Abbreviations: lum.=luminal; b/sb=basal/suprabasal; +/-=very few cells present; scatt.=scattered; UDH=usual ductal hyperplasia; $\mathrm{ADH}=$ atypical ductal hyperplasia; DCIS = ductal carcinoma in situ; CLIS = lobular carcinoma in situ . 
phenotypes both in the luminal cell compartment and in a smaller rate in the basal/suprabasal layers. The proliferative activity of MIB1 + /smooth muscle actin + phenotypes was negligible.

\section{Statistical Difference between the Proliferative Fractions of the Different Lineages in the Different Diagnostic Groups}

There was a statistically significant increase in the proportion of proliferating MIB1 + /CK5/14 + phenotypes in the luminal compartment of usual ductal hyperplasias, whereas the rate of proliferating MIB1 + /CK8/18/19 + glandular phenotype was significantly higher in ductal carcinoma in situ than in the other diagnostic groups $(P<0.05$; MannWhitney $U$-test). In other lesions, no significant difference was computed between the growth fractions of the different phenotypes.

\section{Double-Immunofluorescence Studies}

Using double immunolabeling with digital image processing for simultaneous demonstration of CK5/6, CK8/18/19 and smooth muscle actin in the normal breast, we could identify five distinct immunophenotypes, in concordance with our previous findings: ${ }^{13,14}$ (i) cells expressing only CK5/6, individually dispersed in the luminal layer, especially in the terminal ducts, and in a more irregular distribution within lobules, (ii) CK5/6 + /CK8/18/19 + 'hybrid' glandular cells showing similar distribution, (iii) only CK 8/18/19 + immunophenotypes consistently within the luminal compartment, (iv) CK5/6+/smooth muscle actin + 'hybrid' myoepithelial cells in the basal/parabasal layers and (v) only smooth muscle actin + myoepithelial end cells, exclusively at basal location (Figure 3).

In usual ductal hyperplasias, there was an abundance of proliferating intraductal MIB1+/ CK5/14 + cells in nonfluorescence immunohistochemistry. Most of these cells turned out to coexpress CK5/6 and CK8/18/19 in double-immunofluorescence studies leaving only few cells that express CK5/6 only. These data seem to indicate that CK5/6 + /CK8/18/19 + 'hybrid' glandular phenotypes represent the main proliferating cell compartment in these lesions.

In contrast, atypical ductal hyperplasias and atypical lobular hyperplasias, as well as ductal carcinoma in situ non-high grade and lobular carcinoma in situ expressed exclusively CK8/18/19 in the neoplastic cell population. CK5/6 + /CK8/18/ $19+$ hybrid immunophenotypes were only rarely or not at all detected in these lesions. Considering the luminal location, these cells were interpreted as being residual 'normal' cells. Double staining for CK5/6 and smooth muscle actin showed a mixture of CK $5 / 6+/$ smooth muscle actin + phenotypes and a variable number of smooth muscle actin + myoepithelial end cells with only very few CK5/ $6+/$ smooth muscle actin - cells in the outer cell layer.

Interestingly, in atypical lobular hyperplasia and lobular carcinoma in situ, the CK5/6 + cells were localized both in the basal/suprabasal and luminal layers; in the latter, interspersed with clusters of CK 8/18/19+ neoplastic cells. This indicates that proliferating MIB1 + /CK5/6 + phenotypes are localized in the normal epithelial compartment, which is infiltrated by clusters of neoplastic lobular cells in atypical lobular hyperplasia and lobular carcinoma in situ.

\section{Discussion}

Several studies have investigated the proliferative activity of invasive breast cancer, its precursors and benign breast lesions by various methods during the last decades. ${ }^{22-25}$ The majority of these studies considered breast lesions to be a homogeneous disease with respect to the cellular composition of the growth fraction. In contrast to this view, our previous results, ${ }^{8-12}$ in line with findings of others, ${ }^{26}$ indicated that different cell types are involved in the development and progression of benign proliferative breast diseases on the one hand and of premalignant and malignant breast diseases on the other hand. In addition to the well-known glandular (CK8/18/ $19+$ ) and myoepithelial (smooth muscle actin + ) cells, a third cell type could clearly be identified in the breast parenchyma, which is characterized by the expression of basal-type keratins CK5/14 only. Most recently, based on double-fluorescence immunolabeling and Western blot findings, we proposed that these disseminated, only CK5/14 expressing basal-type cells represent mammary progenitor cells that give rise both to glandular and myoepithelial lineages. ${ }^{13,14}$

In the present study, we assessed the proliferative potential of different immunophenotypes in normal breast tissue, usual ductal hyperplasia, atypical ductal and lobular hyperplasias, as well as in ductal and lobular in situ carcinomas using double-labeled immunohistochemistry for the MIB1 growth fraction and lineage-specific markers. To understand the cell biology aspects of such diverse lesions, we also analyzed a small cohort of representative lesions using commercially available antibodies to CK5/6, CK8/18/19 and smooth muscle actin in doubleimmunofluorescence experiments as previously described. ${ }^{13,14}$

As expected, MIB1 labeling was seen mainly in the CK8/18/19 + and CK5/14 + cell pools, whereas smooth muscle actin + phenotypes rarely showed simultaneous positive MIB1 staining in the normal mammary gland. In accordance with our progenitor cell concept, shown in a schematic drawing in Figure 4, data of the present study indicate that cells 
normal lobule

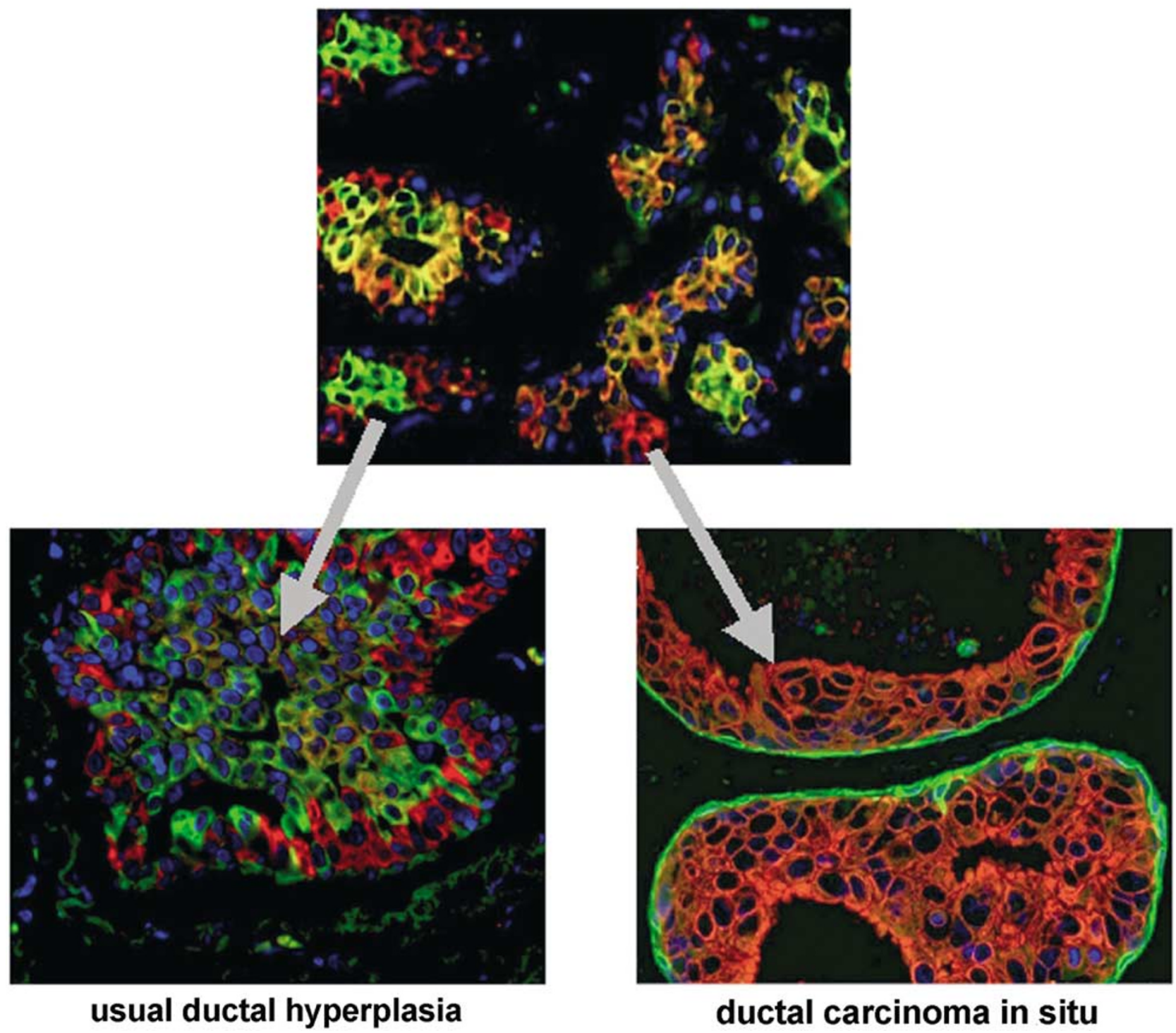

Figure 3 Double-fluorescence immunolabeling of paraffin tissue sections from normal breast lobule, usual ductal hyperplasia and ductal carcinoma in situ non-high grade using monoclonal antibodies specific for CK5/6 and CK8/18/19. In the normal breast lobule, cells expressing only CK5/6 (green), indicating progenitor cell phenotype, are located both in the luminal layer, especially in the terminal ducts (left arrow end), and more irregularly in the acini. Several luminal cells display only red signal, indicative of CK8/18/19 glandular cell phenotype (right arrow end). Additionally, many luminal cells express both CK5/6 and CK8/18/19 (yellow) revealing a transition from CK5/6 + progenitor cells to CK8/18/19 + glandular cells via intermediate 'hybrid' glandular cells. In usual ductal hyperplasia (left arrow head), the luminal epithelium showed a mixed staining pattern of CK5/6 + (green), CK8/18/19+ (red) and hybrid (CK5/6 + /CK8/ $18 / 19+$ ) phenotypes indicating that usual ductal hyperplasias most probably derive from progenitor cells. In contrast, the luminal epithelium in ductal carcinoma in situ non-high grade (right arrow head) was exclusively made up of CK8/18/19 + (red) neoplastic cells, whereas CK5/6 + (green) progenitor cells were located in the basal layer. This suggests that ductal carcinoma in situ non-high grade (and atypical ductal hyperplasia) most probably originate from neoplastic cells committed to the glandular lineage. ${ }^{14}$

with myoepithelial immunophenotype (including CK5/6 + /smooth muscle actin + intermediary and smooth muscle actin + end cells) possess very limited proliferative capacity and therefore represent a relatively stable cell lineage both in normal breast and in the proliferative lesions analyzed. This is surprising, since in double-fluorescence experiments, numerous intermediary myoepithelial cells were found usually indicating that many of the smooth muscle actin + cells are not yet fully differentiated. ${ }^{13,14}$ Nevertheless, our present data seem to suggest that cells once having entered the myoepithelial differentiation pathway lose their proliferative capacity.

In contrast, the glandular cell lineage (including CK5/6 + /CK8/18/19 + intermediary and CK8/18/ $19+$ glandular cells) has a high proliferative activity. This is in line with the relatively immature 
Differential MIB1 growth fraction of normal breast epithelium

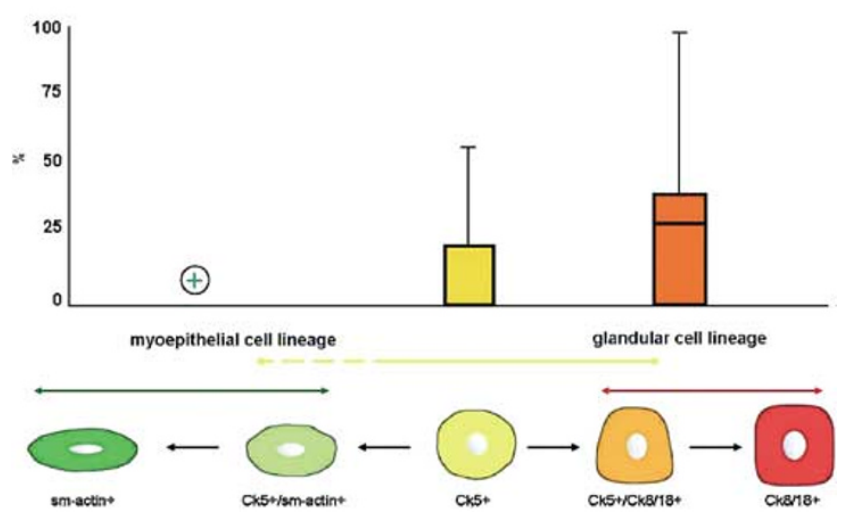

Figure 4 Hypothetical differentiation pathways for normal human breast epithelial cells based on cytokeratin expression profiles and differential MIB1 proliferation rates. Progenitor $(\mathrm{CK} 5+)$ cells give rise either to intermediate glandular (CK5 +) $8 / 18 / 19+$ ) or intermediate myoepithelial cells (CK5 +/smooth muscle actin +$)$. The intermediate glandular cells differentiate further into transit glandular cells (CK8/18/19+) and lactating end cells. The intermediate myoepithelial cells differentiate into myoepithelial end cells (smooth muscle actin + only).

characteristics of luminal epithelium as demonstrated in our double-fluorescence studies. ${ }^{13,14}$ As the frequency of MIB1 + /CK8/18/19+ cells significantly exceeds that of the MIB $1+/ \mathrm{CK} 5 / 14+$ phenotypes we conclude, that CK8/18/19+ glandular cells in the resting breast epithelium still retain a considerable proliferative potential.

From these results alone, we cannot extrapolate the proliferative capacity of only CK5 + cells. Our recent studies provide clear evidence that these cells represent progenitor cells for both the glandular and myoepithelial cell lineages. ${ }^{13,14}$ It is very likely that this cell pool also harbors the proper stem cells of the human breast (Boecker et al, in preparation), the proliferative capacity of which should be rather low, in accordance with stem cells in other tissues. ${ }^{27}$

Usual ductal hyperplasia differed from all other benign lesions because of the statistically significantly increased rate of proliferating MIB1 + /CK5/ $14+$ phenotypes in the luminal compartment, while the proportion of the proliferating glandular phenotypes (CK8/18/19+) was practically unchanged. The presence of proliferating CK5/14+/ CK8/18/19 + 'hybrid' cells in the luminal compartment, as unequivocally identified on serial sections from the same lesion, point to the participation of intermediary glandular cells in the setup of usual ductal hyperplasias. These findings, in keeping with the observation that CK5/14 + phenotypes localize mainly in luminal layers within the normal mammary gland, suggest that these cells may be associated with physiological cell renewal and generation of benign proliferative breast diseases. Based on the functional progenitor cell concept, ${ }^{13}$ we presume that the CK5/14 + epithelial cells represent a pool of multipotent cells (or reserve cells), which upon perturbation by different signals from the microenvironment: (i) differentiate along the glandular lineage, or (ii) proliferate and give rise to hyperplasias. This is in line with results of in vitro studies. ${ }^{28}$ However, the slightly increased risk for the evolution of breast cancer in cases with usual ductal hyperplasia ${ }^{29,30}$ cannot be explained by these studies alone. A direct, stepwise, linear progression of usual ductal hyperplasia to non-high-grade ductal carcinoma in situ, as proposed by some investigators, ${ }^{31-33}$ seems unlikely. Contrarily, several lines of evidence support the biological concept of de novo carcinogenesis in the breast, defining atypical ductal hyperplasia as the 'lowest end' of some of the lowgrade ductal carcinoma in situ. ${ }^{18,34}$

It is not quite clear, however, whether the myoepithelial cells are integral parts of the proliferative diseases or whether they participate in a reactive process. Based on our present findings, the myoepithelial cells do not seem to be involved in the proliferative breast diseases, they rather represent a persisting basal cell layer around the ductallobular structures in the breast parenchyma. However, the molecular studies of Lakhani et $a l^{35}$ showing loss of heterozygosity (LOH) also in myoepithelial cells adjacent to and far away from breast carcinomas, contradict our view.

Intriguingly, in early malignant intraductal breast diseases (atypical ductal hyperplasia) and in situ carcinomas (ductal carcinoma in situ), MIB1 + /CK5/ $14+$ phenotypes were sporadical and confined to the luminal compartment in a very few atypical ductal hyperplasia cases but not in ductal carcinoma in situ non-high grade, compared to usual ductal hyperplasias. In atypical lobular hyperplasia and lobular carcinoma in situ, however, their frequency rate increased. This might be explained by different growth patterns of ductal and lobular neoplasias. While ductal neoplasia replace and destroy normal glandular cells, tumor cells of lobular neoplasias often infiltrate the normal epithelium, leaving the normal epithelial cells in a reticulated pattern between tumor cells. The predominantly expressed cytokeratins in the proliferating neoplastic cell pool were, in fact, the glandular-type keratins (CK8/18/ 19). This is in line with the observation that $>95 \%$ of invasive breast carcinomas express a luminal-like phenotype $(\mathrm{CK} 8 / 18 / 19)^{12,21,36-38}$ indicating that malignant transformation in mammary epithelium occurs in a cell committed to the glandular lineage. ${ }^{15}$ This is further confirmed by the exceptionally rare occurrence of carcinomas with a pure stem cell phenotype (CK5 + /CK8/18/19-/smooth muscle actin-), indicating poor prognosis ${ }^{39}$ and myoepithelial malignancies. ${ }^{40}$

In the present study, we could demonstrate that the monotypic expression of glandular cytokeratins (CK8/18/19) within the growth fraction both in atypical ductal hyperplasia and ductal carcinoma in situ non- high grade is in glaring contrast to the heterogeneous morphology and mixed immunophenotype of usual ductal hyperplasias. 
Nevertheless, a small fraction of poorly differentiated in situ and invasive ductal carcinomas might evolve directly from CK5/14 + or intermediary CK5/ $14+/ \mathrm{CK} 8 / 18 / 19+$ cells, as some of these tumors express both keratin subgroups (not shown in this study). This indicates alternative pathways in breast carcinogenesis, as reflected by recent cytogenetic and adhesion molecule studies from our group, as well. ${ }^{41,42}$

We conclude that in both the normal breast and benign proliferative breast diseases, there is a heterogeneous proliferation of progenitor, glandular, and myoepithelial cells as well as their intermediary antecedents in different proportions. In contrast, intraductal neoplastic breast lesions (atypical ductal hyperplasia and ductal carcinoma in situ non-high grade), are composed of one proliferating cell type, namely malignantly transformed glandular epithelial cells. The importance of this finding for the routine pathology is that the determination of the immunophenotypic composition of the growth fraction enables differential diagnosis in morphologically ambiguous cases, for example, usual ductal hyperplasia vs atypical ductal hyperplasia, the different evolutional traits of which can readily be illustrated by the adult progenitor cell hypothesis. ${ }^{13,14}$ Hence, we propose this concept as an operative model for understanding the histogenesis of benign and malignant breast diseases.

\section{References}

1 Dawson EK. A histological study of the normal mamma in relation to tumour growth. I. Early development to maturity. Edinb Med J 1934;41:653-682.

2 Moll R, Franke WW, Schiller DL, et al. The catalog of human cytokeratins: patterns of expression in normal epithelia, tumors and cultured cells. Cell 1982;31: 11-24.

3 Bartek J, Bartkova J, Taylor Papadimitriou J, et al. Differential expression of keratin 19 in normal human epithelial tissues revealed by monospecific monoclonal antibodies. Histochem J 1986;18:565-575.

4 Taylor-Papaimitriou J, Lane EB. Keratin expression in the mammary gland. In: Neville MC, Daniel CW (eds). The Mammary Gland: Development, Regulation and Function. Plenum: New York, 1987, pp 181-215.

5 Hudson DL, O'Hare M, Watt FM, et al. Proliferative heterogeneity in the human prostate: evidence for epithelial stem cells. Lab Invest 2000;80:1243-1250.

6 Jones PH, Harper S, Watt FM. Stem cell patterning and fate in human epidermis. Cell 1995;80:83-93.

7 Li A, Simmons PJ, Kaur P. Identification and isolation of candidate human keratinocyte stem cells based on cell surface phenotype. Proc Natl Acad Sci USA 1998;95:3902-3907.

8 Jarasch ED, Nagle RB, Kaufmann M, et al. Differentail diagnosis of benign epithelial proliferations and carcinomas of the breast using antibodies to cytokeratins. Hum Pathol 1988;19:276-289.

9 Böcker W, Bier B, Freytag G, et al. An immunohistochemical study of the breast using antibodies to basal and luminal keratins, alpha-smooth muscle actin, vimentin, collagen IV and laminin. Part I: Normal breast and benign proliferative lesions. Virchows Arch 1992;421:315-322.

10 Böcker W, Bier B, Freytag G, et al. An immunohistochemical study of the breast using antibodies to basal and luminal keratins, alpha-smooth muscle actin, vimentin, collagen IV and laminin. Part II: Epitheliosis and ductal carcinoma in situ. Virchows Arch 1992; 421:323-330.

11 Perou CM, Sorlie T, Eisen MB, et al. Molecular portraits of human breast tumors. Nature 2000;406: 747-752.

12 Böcker W, Bier B, Ludwig A, et al. Benign proliferative lesions and in situ carcinoma of the breast: new immunohistological findings and their biological implications. Eur J Cancer Prev 1993;2:41-49.

13 Böcker W, Moll R, Poremba C, et al. Common adult stem cells in the human breast give rise to glandular and myoepithelial cell lineages: a new cell biological concept. Lab Invest 2002;82:737-745.

14 Böcker W, Moll R, Dervan P, et al. Usual ductal hyperplasia of the breast is a committed stem (progenitor) cell lesion distinct from atypical ductal hyperplasia and ductal carcinoma in situ. J Pathol 2002;198:458-467.

15 Korsching E, Packeisen J, Agelopoulos K, et al. Cytogenetic alterations and cytokeratin expression patterns in breast cancer: integrating a new model of breast differentiation into cytogenetic pathways of breast carcinogenesis. Lab Invest 2002;82:1525-1533.

16 Elston CW, Ellis IO. Pathological prognostic factors in breast cancer. I. The value of histological grade in breast cancer: experience from a large study with long term follow up. Histopathology 1991;19:403-410.

17 Holland R, Peterse JL, Millis RR, et al. Ductal carcinoma in situ: a proposal for a new classification. Semin Diagn Pathol 1994;11:167-180.

18 Page DL, Rogers LW. Combined histologic and cytologic criteria for the diagnosis of mammary atypical ductal hyperplasia. Hum Pathol 1992;23:1095-1097.

19 Silverstein MJ, Poller DN, Wain JR, et al. Prognostic classification of breast ductal carcinoma-in-situ. Lancet 1995;345:1154-1157.

20 Sloane JP (ed). Biopsy Pathology of the Breast, 2nd edn. Arnold: London, 2001.

21 Nagle RB, Böcker W, Davis JR, et al. Characterization of breast carcinomas by two monoclonal antibodies distinguishing myoepithelial from luminal epithelial cells. J Histochem Cytochem 1986;34:869-881.

22 Lelle RJ, Heidenreich W, Stauch G, et al. The correlation of growth fractions with histologic grading and lymph node status in human mammary carcinoma. Cancer 1987;59:83-88.

23 Wintzer HO, Zipfel I, Schulte MJ, et al. Ki-67 immunostaining in human breast tumors and its relationship to prognosis. Cancer 1991;67:421-428.

24 Pavelic ZP, Pavelic EE, Lower M, et al. C-myc, c-erbB2, and Ki-67 expression in normal breast tissue and in invasive and noninvasive breast carcinoma. Cancer Res 1992;52:2597-2602.

25 Bai M, Agnantis NJ, Kamina S, et al. In vivo cell kinetics in breast carcinogenesis. Breast Cancer Res 2001;3:276-283.

26 Wetzels RH, Kuijpers HJ, Lane EB, et al. Basal cellspecific and hyperproliferation-related keratins in human breast cancer. Am J Pathol 1991;138:751-763. 
27 Wright NA. Epithelial stem cell repertoire in the gut: clues to the origin of cell lineages, proliferative units and cancer. Int J Exp Pathol 2000;81:117-143.

28 Taylor-Papadimitriou J, Stampfer M, Bartek J, et al. Keratin expression in human mammary epithelial cells cultured from normal and malignant tissue: relation to in vivo phenotypes and influence of medium. J Cell Sci 1989;94:403-413.

29 London SJ, Connolly JL, Schnitt SJ, et al. A prospective study of benign breast disease and the risk of breast cancer. JAMA 1992;267:941-944.

30 Page DL, Dupont WD. Anatomic indicators (histologic and cytologic) of increased breast cancer risk. Breast Cancer Res Treat 1993;28:157-166.

31 Wellings SR, Jensen HM, Marcum RG. An atlas of subgross pathology of the human breast with special reference to possible precancerous lesions. J Natl Cancer Inst 1975;55:231.

32 Dupont WD, Page DL. Risk factors for breast cancer in women with proliferative breast diseases. N Engl J Med 1985;312:146-152.

33 Carter CL, Corle DK, Mieozzi MS, et al. A prospective study of the development of breast cancer in 16692 women with benign breast disease. Am J Epidemiol 1988;128:467-477.

34 Ellis IO, Pinder SE, Lee AH, et al. A critical appraisal of existing classification systems of epithelial hyperplasia and in situ neoplasia of the breast with proposals for future methods of categorisation: where are we going? Semin Diagn Pathol 1999;16: 202-208.
35 Lakhani SR, Chaggar R, Davies S, et al. Genetic alterations in 'normal' luminal and myoepithelial cells of the breast. J Pathol 1999;189:496-503.

36 Dairkee SH, Puett HL, Hackett AJ. Expression of basal and luminal epithelium-specific keratins in normal, benign and malignant breast tissue. J Natl Cancer Inst 1988;80:691-695.

37 Guelstein VI, Tchypysheva TA, Ermilova VD, et al. Monoclonal antibody mapping of keratins 8 and 17 and of vimentin in normal human mammary gland, benign tumors, dysplasias and breast cancer. Int J Cancer 1988;42:147-153.

38 Ronnov-Jessen L, Petersen OW, Bissel MJ. Cellular changes involved in conversion of normal to malignant breast: importance of stromal reaction. Physiol Rev 1996;76:69-125.

39 van de Rijn M, Perou CM, Tibshirani R, et al. Expression of cytokeratins 17 and 5 identifies a group of breast carcinomas with poor clinical outcome. Am J Pathol 2002;161:1991-1996.

40 Lakhani SR, O'Hare MJ. The mammary myoepithelial cell-Cinderella or ugly sister? Breast Cancer Res 2001;3:1-4.

41 Bánkfalvi A, Terpe HJ, Breukelmann D, et al. Gains and losses of CD44 expression during breast carcinogenesis and tumour progression. Histopathology 1998;33: 107-116.

42 Buerger H, Otterbach F, Simon R, et al. Comparative genomic hybridization of ductal carcinoma in situ of the breast-evidence of multiple genetic pathways. J Pathol 1999;187:396-402. 